\title{
Access to waitlisting for deceased donor kidney transplantation in Australia
}

Authors: Matthew P Sypek ${ }^{1,2,3}$, Philip A Clayton ${ }^{1,4,5}$, Wai Lim ${ }^{6,7}$, Peter Hughes ${ }^{2,3}$, John Kanellis ${ }^{8}$, Jenni Wright $^{9}$, Jeremy Chapman ${ }^{9}{ }^{10}$, Stephen P McDonald ${ }^{1,4,5}$

\footnotetext{
${ }^{1}$ ANZDATA Registry, Adelaide, Australia

${ }^{2}$ Dept of Medicine, Dentistry and Health Sciences, University of Melbourne, Australia

${ }^{3}$ Dept of Nephrology, Royal Melbourne Hospital, Australia

${ }^{4}$ Central and Northern Renal and Transplantation Services, Central Adelaide Local Health Network, Adelaide, Australia

${ }^{5}$ Adelaide Medical School, University of Adelaide, Australia

${ }^{6}$ Renal Department, Sir Charles Gairdner Hospital, Perth, Australia

${ }^{7}$ School of Medicine and Pharmacology, University of Western Australia, Australia

${ }^{8}$ Department of Nephrology, Monash Health and Centre for Inflammatory Diseases, Department of Medicine, Monash University, Melbourne, Australia

${ }^{9}$ National Organ Matching System, Australian Red Cross Blood Service, Sydney, Australia

${ }^{10}$ Department of Renal Medicine, Westmead Hospital, Sydney, Australia
}

Corresponding Author:

Dr Matthew Sypek

ANZDATA Registry, c/o SAHMRI, North Tce, Adelaide, Australia, 5000

matthew@anzdata.org.au

p. +61881284767

Running title:

Transplant waitlisting in Australia

Conflict of interest declaration:

We hereby declare that the results presented in this paper have not been published previously, in whole or in part, except in abstract format. The authors declare that they do not have any conflicts of interest relevant to this manuscript.

This is the author manuscript accepted for publication and has undergone full peer review but has not been through the copyediting, typesetting, pagination and proofreading process, which may lead to differences between this version and the Version of Record. Please cite this article as doi: $10.1111 /$ nep.13484

This article is protected by copyright. All rights reserved. 


\section{Abstract:}

Background:

A detailed analysis of waitlisting for deceased donor kidney transplantation in Australia has not previously been reported. We aimed to determine if patient characteristics associated with waitlisting identify areas of potential inequality in access to transplantation in Australia.

Methods:

A competing risk time-to-event model was used to determine predictors of waitlisting for all adult incident renal replacement therapy patients in Australia between 2006-2015. Secondary analysis was performed to determine predictors of overall access to transplantation (using a combined outcome of waitlisting and living donor transplantation).

Results:

The cohort consisted of 21,231 patients with a median age of 63 years. Overall, 4,361 (20.5\%) were waitlisted and 1,239 (5.8\%) received a living donor transplant without being previously waitlisted. Primary analysis revealed that medical comorbidities, older age, smoking status and body mass index, were all significant predictors of waitlisting and that and there was variation in waitlisting practice across states Despite adjustment for the above factors, demographic characteristics including Indigenous ethnicity (SHR 0.46, [95\% $\mathrm{Cl} 0.38-0.55])$, female gender (SHR 0.46, [95\% Cl 0.38- 
$0.55])$, and residence in a regional area (SHR 0.88 [95\% Cl 0.81-0.95]) were also associated with a lower likelihood of waitlisting.

Secondary analysis showed younger age and higher socioeconomic advantage were additional predictors of overall access to transplantation, driven by higher rates of living donor transplantation.

Conclusion:

Demographic as well as clinical characteristics are associated with reduced likelihood of waitlisting for kidney transplantation in Australia. Further analysis and auditing should be considered to determine if this reflects other, unmeasured factors or highlights a need to address inequality.

Keywords:

Kidney Transplant, Waitlist, Access, Equity, 


\section{Main Text:}

\section{Background}

For many patients with end stage kidney disease (ESKD), transplantation offers superior survival and quality of life compared to dialysis, and is associated with reduced burden of health care costs (1-4). In Australia, around $75 \%$ of renal transplants come from deceased donors(5). The Australia and New Zealand Dialysis and Transplantation Registry (ANZDATA) publishes annual waitlist stock and flow data (6), however, a detailed analysis of the predictors of transplant waitlisting for incident renal replacement therapy (RRT) patients in Australia has not been previously reported.

Studies in the United States(7,8), United Kingdom(9,10), Canada(11), France(12,13) and other transplantation jurisdictions(14) have consistently found inequalities in completion of transplant work up and waitlisting for patients on dialysis based on patient factors including race, gender, socioeconomic status and regional factors. Commentary based on publicly available registry data has questioned the low proportion of prevalent dialysis patients on the renal transplant waitlist in Australia(15) and qualitative analysis of nephrologists' perspectives on waitlisting has revealed tensions between advocating for the best treatment for their own patients, maintaining professional integrity and protecting centre reputation, and maximising societal benefit(16). Although small, single centre audits have helped identify some barriers to timely transplant waitlisting(17), a review of national practice is required to understand current waitlisting practices and identify potential areas of inequality that may require targeted interventions.

This article is protected by copyright. All rights reserved. 
The Transplantation Society of Australia and New Zealand (TSANZ) provides guidance on recipient eligibility criteria for deceased donor kidney transplant waitlisting(18). In order to be eligible for waitlisting in Australia a person must be receiving dialysis for the treatment of ESKD, have a low anticipated likelihood of perioperative mortality, and have an anticipated $80 \%$ likelihood of survival at five years post-transplantation. It is acknowledged that based on these criteria, some patients who might benefit from a kidney transplant will be deemed ineligible for listing.

The National Health and Medical Research Council's (NHRMC) 'Ethical guidelines for organ transplantation from deceased donors' state that there must be no unlawful or unreasonable discrimination against potential recipients based on a number of factors including, but not limited to; race, cultural beliefs, gender, age, disability, social status, sexual preference, location of residence or capacity to pay for treatment(19).

We aimed to provide a detailed description of access to waitlisting for renal transplantation in Australia for incident RRT patients and determine if patient factors associated with access to transplantation identify potential inequalities that may require further investigation or targeted interventions.

\section{Methods}

\section{Data Sources:}

A de-identified data extract from the ANZDATA registry was used in the analysis. ANZDATA is a binational clinical quality assurance registry that collects data on all patients receiving RRT for ESKD in Australia and New Zealand. Waitlist data from the National Organ Matching System (NOMS), an 
Australia wide database and application used in maintaining the kidney waitlist, organ donor testing and organ allocation is incorporated into the ANZDATA database for auditing and reporting purposes. ANZDATA collects data from all patients receiving RRT in Australia and New Zealand under an opt-out consent process approved by the Central Adelaide Local Health Network Human Research Ethics Committee. Data on waitlisting in New Zealand were not available for this analysis.

\section{Inclusion/exclusion criteria:}

All incident RRT patients in Australia during the 10-year period from $1^{\text {tst }}$ July 2006 to $30^{\text {th }}$ June 2015 were included in the analysis. Patients aged less than 18 years at the time of commencing RRT were excluded. Patients who were waitlisted for multi-organ transplants were excluded, as were those who had recovery of native renal function sufficient to cease RRT. Patients who received deceased donor kidney transplants prior to waitlisting $(n=7)$ were excluded, these may include data errors or exceptional clinical circumstances.

\section{Outcome:}

The primary outcome was time to first active waitlisting for deceased donor transplantation. Death and living donor transplantation were considered competing events. Patients were censored at 31st December 2015 or date of last follow up. Secondary analyses were conducted both with living donor transplant as the outcome of interest and with a combined endpoint of deceased donor waitlisting or living donor transplantation.

\section{Predictors:}

The following predictor variables were examined: year of commencing RRT, age at commencing RRT, gender, primary cause of ESKD, comorbidities at time of commencing RRT (vascular disease (a 
composite of ischaemic heart disease, peripheral vascular disease and cerebrovascular disease), chronic lung disease, diabetes as a comorbid condition (i.e. presence of diabetes in patients whose primary renal disease is not diabetic nephropathy), smoking status, history of non-skin cancer), body mass index (BMI), late referral to a nephrologist (commencement of RRT within 90 days of referral), Indigenous ethnicity, state in which RRT was commenced, quintile of socio-economic disadvantage (derived from the Australia Bureau of Statistics (ABS) Socio-Economic Indexes for Areas (SEIFA) )(20) and remoteness based on postcode of residence (collapsed to three categories)(21).

\section{Statistical analysis:}

Characteristics of the cohort are reported. The observed first outcome for patients with sufficient follow up time at specified time points ( 6 months, 1 , and 5 years) post commencing RRT is reported by age group.

Survival analysis was conducted using competing risk time to event regression models using methods described by Fine and Gray(22), with results presented as subdistribution hazard ratios (SHR). Continuous variables (age and BMI) were categorised into clinically relevant groupings. SHR for states are presented relative to the balanced grand mean of all states. Predictors were considered for inclusion in the multivariate model if significant on univariate analysis using a $p$ value threshold of $<0.2$. The proportional subhazard assumption was tested using visual inspection of plotted Schoenfeld residuals. Where there were violations of this assumption, time dependent covariates were introduced to create a piecewise model. Time varying covariates were created for 3 predictor variables, non-skin cancer, smoking history and late referral, with separate subhazard ratios estimated for each time period. 
Tests were considered to be statistically significant at a $p$ value $<0.05$. Analyses were conducted in Stata/IC 15.1 (StataCorp, College Station TX, USA).

\section{Results:}

Population:

A total of 21,213 incident RRT patients were included in the analysis. The median age was 63 years old (IQR 51-73) and $38.2 \%$ of patients were female. Table 1 shows the characteristics of the overall cohort. The median follow-up time was 3.02 years (IQR 1.46-5.25). At the completion of the follow up period a total of 4,361 patients (20.6\%) had been waitlisted, $1,239(5.8 \%)$ had received a living donor (LD) transplant without being listed and 7,800 (36.8\%) had died without being ever waitlisted (table 2).

\section{Observed outcome at specified timepoints:}

Overall, $6.7 \%$ of patients were waitlisted by 6 months after commencing RRT, this increased to $12.1 \%$ at 1 year and $21.3 \%$ at 5 years for patients with a sufficient duration of follow up time to observe all outcomes. An additional 4.3\%, 5.0\% and 6.6\% had received a living donor transplant without previously being waitlisted by 6 months, 1 year and 5 years respectively. There was a substantial difference in outcome a specified time points between age groups (Figure 1). By 1 year post commencing RRT, $33.0 \%$ of $18-24$ year-old patients had been waitlisted, with $22 \%$ having received a LD transplant without being listed and 2.2\% dying without being listed or transplanted. This compares with $15.3 \%$ of $55-64$ year-old patients being listed, $5.1 \%$ receiving a LD transplant and 
$8 \%$ dying prior to other endpoints. Only 2 of the 4,301 patients over the age of 75 years at time of commencing RRT prior to 2015 were waitlisted by 1 year.

\section{Survival Analysis:}

The cumulative incidence for each competing outcome by age group is shown in figure 2 .

The results of univariate and multivariate models are shown in table 3 . All predictor variables, with the exception of year of commencing RRT, were significantly associated with the primary outcome of deceased donor waitlisting on univariate analysis. In the fully adjusted model, all comorbidities included (diabetes, vascular disease, respiratory disease, history of cancer) were associated with a lower likelihood of waitlisting, as were older age groups. There was a difference in waitlisting practice across a number of Australian states, although some significant associations seen on univariate analysis were attenuated in the multivariate model.

Indigenous patients were less likely to be waitlisted or transplanted compared to non-indigenous patients (SHR 0.46, [95\% Cl 0.38-0.55]), as were female patients compared to males (SHR 0.85, [95\% $\mathrm{Cl} 0.80-0.91])$. Residing in a regional area was associated with a reduced likelihood of waitlisting compared to urban patients $(0.88,[95 \% \mathrm{Cl} 0.81-0.95])$, however, remote location did not have a significant association in the adjusted model. The association of socioeconomic disadvantage and reduced likelihood of waitlisting seen on univariate analysis was not seen in the fully adjusted model.

Both underweight and obese patients were less likely to be waitlisted or transplanted compared to patients in the normal BMI range (SHR 0.81 [95\% $\mathrm{Cl} 0.67-0.97], 0.83$ [95\% $\mathrm{Cl} 0.76-0.89]$, respectively). 
The association between cigarette smoking at time of commencing RRT and waitlisting was only seen in the first 12 months of RRT, and was stronger for current smokers than for former smokers (SHR 0.47 [95\% $\mathrm{Cl} 0.41-0.55]$ and 0.81 [95\% $\mathrm{Cl} 0.75-0.88]$, respectively, comparisons to the nonsmoking group). The negative effect of late referral to a nephrologist was most pronounced in the first six months after starting RRT (SHR 0.45 [95\% Cl 0.39-0.53]) and was actually associated with increased waitlisting in the period later than 12 months after starting RRT (SHR $1.22[95 \% \mathrm{Cl}$ $1.09,1.37])$.

Secondary analyses of overall access to transplantation (a composite endpoint of deceased donor waitlisting and living donor transplantation) and of living donor transplantation are also reported in table 3 (models 2 and 3, respectively). Of note, in the combined model, younger age groups (18-24 and 25-39) and patients with higher socioeconomic advantage (SEIFA $4^{\text {th }}$ and $5^{\text {th }}$ quintiles) were more likely to receive living donor transplants and had greater overall access to transplantation compared to the reference populations (age 40-54 and SEIFA $3^{\text {rd }}$ quintile, respectively)

\section{Discussion}

We present the first detailed description of kidney transplant deceased donor waitlisting practice for adults with incident ESKD in Australia and report factors associated with waitlisting in this population. This study confirms a number of expected findings, including that increased comorbid burden and older age are strongly associated with a decreased likelihood of waitlisting, and also highlights variations across specific populations that require further exploration to determine if these observed differences represent inequities that may require targeted interventions.

Although age is not a specific criterion for kidney transplant waitlisting in Australia, there is an association between older age and risk of death as well as age and comorbid burden. The decreased 
rate of waitlisting for older patients may represent appropriate implementation of TSANZ guidelines on excluding patients with $<80 \%$ anticipated 5-year survival post-transplant from the waiting list. However, numerous studies have demonstrated that transplantation confers a survival advantage for elderly patients compared to remaining on dialysis for those deemed suitable for transplantation(2,23-25), albeit in a highly selected cohort. Furthermore, although studies are limited, there are likely to be quality of life and economic benefits of transplantation for this population also(26).

Patients aged 65 years and older accounted for $46 \%$ of all new incident RRT patient in Australia in 2015(27) but made up only $7.3 \%$ of patients active on the transplant list at the end of that year(6). By contrast, older people represent a growing proportion of the kidney transplant waiting list in many countries with the percentage of patients aged 65 years and older on the US waitlist increasing from $14.5 \%$ in 2005 to $22 \%$ in 2015 (28). International practice varies widely with a 2012 study showing transplant listing rates for patients starting RRT aged $>65$ years of up to $24 \%$ in Norway, compared to $\sim 6 \%$ in Austria, Scotland and the Netherlands(14). Of note, a study of elderly patients transplanted in Norway between 1990-2005 reported an 5 year actuarial survival post-transplant of $56 \%$ in patients aged 70 years and older and $72 \%$ in patients aged $60-69$ years(29), suggesting that a substantial number of older patients listed in Norway would not meet the criterion for listing used in Australia. As the number of older persons reaching ESKD continues to increase, it is important that patients are educated about all treatment options, including supportive care and transplantation, and that decisions regarding waitlisting for transplantation are based on consideration of the individual's best interests as well as appropriate resource utilisation whilst avoiding discrimination based on age.

This article is protected by copyright. All rights reserved. 
Australia's Indigenous population experiences a disproportionally high burden of chronic disease compared to non-indigenous Australians(30), including kidney disease, with rates of RRT eightfold higher in the Indigenous population(31). Reduced access to transplant waitlisting and transplantation for Indigenous people has previously been reported(32) and post-transplant outcomes are poorer for Indigenous recipients(33). Recent qualitative research examining the views of Indigenous patients on kidney transplantation has highlighted an intense interest in transplantation within this community, undermined by limited knowledge about transplantation and multiple barriers to effective communication with health professionals(34). Efforts to improve equity in access to transplantation for Indigenous Australians not only require a better understanding of the factors that predict outcomes in this population, but will also rely on developing collaborative partnerships with Indigenous communities to address specific barriers to access.

We found significant differences in waitlisting and transplantation practice based on geographical location in Australia, similar to many other countries $(8-10,12)$. A number of factors vary across states including patient demographics, health system structure and the clinical cultures that individuals work within. For example, the Northern Territory (NT) has the highest percentage of Aboriginal and Torres Strait Islander people (25.5\% compared with the national average of $2.8 \%(35))$ many of whom live remotely; following adjustment for these factors, commencing RRT in the NT was not associated with reduced access to waitlisting. The variation across other states may reflect other, unmeasured population differences. In our secondary analysis, we found that two states (Western Australia and Tasmania) that were less likely to waitlist patients were associated with higher rates of living donor transplantation. Each geographical region comprises multiple autonomous parent renal units, and practice may vary between units in the same region. Further centre level analysis that was beyond the scope of this study is required to determine if variation in 
waitlisting practice across Australia represents appropriate implementation of national guidelines based on local population characteristics or whether interventions may be required to standardize opportunities for patients across the country.

In access to kidney transplantation, as in many aspects of health care and broader society, women experience a systemic disadvantage compared to men. Our finding that after adjustment for other factors, women remained $15 \%$ less likely to be waitlisted is consistent with international experience $(12,36,37)$. And our observed lower likelihood of living donor transplantation for women is consistent with the well documented higher proportion of female-to-male compared to male-tofemale living donors(38). These gender discrepancies likely represent a complex of biological and sociocultural determinants(39-41). Segev et al reported that age and comorbidities were effect modifiers of gender disparities in access to renal transplantation in the US population, concluding that there was no disparity for women in general but rather marker disparity for older women and those with comorbidities(37). We saw the effect size of female gender increase in our multivariate model compared with univariate analysis (SHR 0.85 vs 0.91 ), however, the exploration of effect modifiers was beyond the scope of this paper. Further analysis, clinical auditing and patient engagement is needed to identify and work towards eliminating any systematic or cultural genderbased discrimination that is contributing to these observed differences.

While there was no association between younger age groups (18-24 and 25-39, compared with the reference group 40-54) or more socioeconomically advantaged groups and waitlisting on our primary analysis, secondary analysis using a composite endpoint of waitlisting or living donor transplantation showed significant advantages for these groups. This is consistent with our previously reported finding that socioeconomic status is associated with lower rates of living, but not 
deceased donor kidney transplantation in Australia(42). Studies in the United States have also reported an association between markers of socio-economic prosperity such as insurance status and successful completion of transplantation work up $(7,43)$. This finding highlights the importance of considering all potential pathways to transplantation for incident RRT patients when assessing equity of access and targeting interventions to address this.

As with any registry-based study, our conclusions are limited by the variables available. We chose to include only the major comorbidities reported to ANZDATA which are more universally collected than the free text 'other comorbidity' field. We also used only comorbidities reported at time of commencing RRT rather than those that developed whilst on dialysis but prior to listing to simplify our models. Information about reasons for not listing was not available and in many cases, may have reflected patient choice or other unmeasured factors such as additional comorbidities or adherence to medical therapy. Our dataset was also unable to accurately identify other vulnerable population groups such as recent migrants or persons with mental health conditions, who may also be at risk of reduced access to transplantation. Our analysis provides a broad overview of factors that predict access to transplantation; further analysis such as multilevel modelling, detailed exploration of variable interactions and clinical auditing that was beyond the scope of this paper, may yield further insights into waitlisting practice.

\section{Conclusion}

We present the first detailed description of kidney transplant waitlisting practices in Australia. It is expected that factors associated with poor outcome post transplantation such as comorbid medical conditions and older age would also be associated with lower likelihood of waitlisting, and these finding likely represent appropriate implementation of current guidelines. However, we also 
highlight differences in access to waitlisting based on a number of additional demographic factors including gender, ethnicity and location of residence. Further analysis and clinical audit are required to determine if these differences represent other, unmeasured factors or whether targeted interventions are required to improve equity in access to waitlisting in Australia.

\section{Acknowledgements:}

The data reported here have been supplied by the Australia and New Zealand Dialysis and Transplant Registry. The interpretation and reporting of these data are the responsibility of the authors and in no way should be seen as an official policy or interpretation of the Australia and New Zealand Dialysis and Transplant Registry.

The authors would like to acknowledge the National Organ Matching Services (NOMS) and the renal units who voluntarily contribute to the ANZDATA registry for the data used in this analysis.

Funding for this work was in part provided by the Better Evidence and Translation in Chronic Kidney Disease (BEAT CKD) NHMRC Project Grant.

This article is protected by copyright. All rights reserved. 


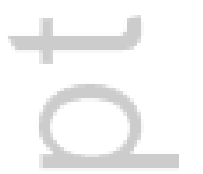

4 


\section{$\underline{\text { References }}$}

1. Wolfe R, Ashby V, Mildfor E, et al. Comparison of mortality of all patients on dialysis, patients on dialysis awaiting transplantation, and recipients of a first cadaveric transplant. N Engl J Med. 1999;341:1725-30.

2. Oniscu GC, Brown H, Forsythe JLR. How great is the survival advantage of transplantation over dialysis in elderly patients? Nephrol Dial Transplant. 2004;19:945-51.

3. Tonelli M, Wiebe N, Knoll G, et al. Systematic Review : Kidney Transplantation Compared With Dialysis in Clinically Relevant Outcomes. Am J Transpl. 2011;11:2093-109.

4. Wong G, Howard K, Chapman JR, et al. Comparative Survival and Economic Benefits of Deceased Donor Kidney Transplantation and Dialysis in People with Varying Ages and CoMorbidities. PLoS One. 2012;7:1-9.

5. ANZDATA Registry. 39th Report, Chapter 8: Transplantation. [Internet]. 2016 [cited 2018 Jan 14]. Available from: http://www.anzdata.org.au/v1/annual_reports_download.html

6. ANZDATA Registry. 39th Annual Report, Chapter 7: Australian Waiting List ANZDATA Registry [Internet]. 2016 [cited 2018 Jan 14]. Available from:

http://www.anzdata.org.au/v1/annual_reports_download.html

7. Monson RS, Kemerley P, Walczak D, Benedetti E, Oberholzer J. Disparities in Completion Rates of the Medical Prerenal Transplant Evaluation by Race or Ethnicity and Gender. Transplantation. 2015;99:236-42.

This article is protected by copyright. All rights reserved. 
8. Patzer RE, Amaral S, Wasse H, Volkova N, Kleinbaum D, Mcclellan WM. Neighborhood Poverty and Racial Disparities in Kidney Transplant Waitlisting. J Am Soc Nephrol. 2009;20:1333-40.

9. Dudley CRK, Johnson RJ, Thomas HL, Ravanan R, Ansell D. Factors That Influence Access to the National Renal Transplant Waiting List. Transplantation. 2009;88:96-102.

10. Akolekar D, Oniscu GC, Forsythe JLR. Variations in the Assessment Practice for Renal Transplantation Across the United Kingdom. Transplantation. 2008;85:407-10.

11. Kiberd B, Boudreault J, Bhan V, Panek R. Access to the Kidney Transplant Wait List. Am J Transpl. 2006;6:2714-20.

12. Bayat S, Macher MA, Couchoud C, et al. Individual and Regional Factors of Access to the Renal Transplant Waiting List in France in a Cohort of Dialyzed Patients. Am J Transpl. 2015;15:1050-60.

13. Lefort $M$, Vigneau $C$, Laurent $A$, et al. Facilitating access to the renal transplant waiting list does not increase the number of transplantations : comparative study of two French regions. Clin Kidney J. 2016;9:849-57.

14. Stel VS, Kramar R, Leivestad T, et al. Original Articles Time trend in access to the waiting list and renal transplantation : a comparison of four European countries. Nephrol Dial Transplant. 2012;27:3621-31

15. Pussell BA, Bendorf A, Kerridge IH. Access to the kidney transplant waiting list : a time for reflection. Intern Med J. 2012;42:360-3.

16. Tong A, Howard K, Wong G, et al. Nephrologists' Perspectives on Waitlisting and Allocation of 
Deceased Donor Kidneys for Transplant. AJKD. 2017;58:704-16.

17. Ducharlet $K$, Roberts MA, Lee $D$. Identifying the barriers to timely transplant waitlisting. Nephrology. 2016;21:443.

18. The Transplantation Society of Australia and New Zealand (TSANZ). Clinical Guidelines for Organ Transplantation from Deceased Donors [Internet]. 2017 [cited 2017 May 16]. Available from:

https://www.tsanz.com.au/organallocationguidelines/documents/ClinicalGuidelinesV1.1May 2017.pdf

19. National Health and Medical Reserach Council. Ethical guidelines for organ transplantation from deceased donors [Internet]. 2016 [cited 2017 Dec 10]. Available from: https://www.nhmrc.gov.au/guidelines-publications/e76

20. Australian Bureau of Statistics. Socio-economic indexes for areas [Internet]. 2017 [cited 2017 Dec 12]. Available from: http://www.abs.gov.au/ausstats/abs@.nsf/mf/2033.0.55.001

21. Australian Bureau of Statistics. Australian Statistical Geography Standard ( ASGS ): Volume 5 Remoteness Structure Australia [Internet]. 2011 [cited 2017 Dec 12]. Available from: http://www.abs.gov.au/ausstats/abs@.nsf/mf/1270.0.55.005

22. Fine JP, Gray RJ. A Proportional Hazards Model for the Subdistribution of a Competing Risk. J Am Stat Assoc. 1999;94:496-509.

23. Rao PS, Merion RM, Ashby VB, Port FK, Wolfe RA. Renal Transplantation in Elderly Patients Older Than 70 Years of Age : Results From the Scientific Registry of Transplant Recipients. Transplantation. 2007;83:1069-74.

This article is protected by copyright. All rights reserved. 
24. Johnson D, Herzig K, Purdie D, et al. A Comparison of the Effects of Dialysis and Renal Transplantation on the Survival of Older Uremic Patients. Transplantation. 2017;69:794-9.

25. Bayat S, Kessler M, Briancon S, Frimat L. Survival of transplanted and dialysed patients in a French region with focus on outcomes in elderly. Nephrol Dial Transplant. 2017;25:292-300.

26. Segall L, Nistor I, Pascual J, et al. Criteria for and Appropriateness of Renal Transplantation in Elderly Patients With End-Stage Renal Disease : A Literature Review and Position Statement on Behalf of the European Renal Association-European Dialysis and Transplant Association. Transplantation. 2016;100:55-65.

27. ANZDATA Registry. 39th Annual Report, Chapter 1: Incidence of End Stage Kidney Disease [Internet]. 2016 [cited 2018 Jan 14]. Available from:

http://www.anzdata.org.au/v1/annual_reports_download.html

28. Hart A, Smith JM, Skeans MA, et al. OPTN / SRTR 2015 Annual Data Report : Kidney. Am J Transplant. 2015;17(S1):21-116.

29. Heldal K, Leivestad T, Hartmann A, Svendsen MV, Lien BH, Midtvedt K. Kidney transplantation in the elderly - the Norwegian experience. Nephrol Dial Transplant. 2008;23:1026-31.

30. Vos T, Barker B, Begg S, Stanley L, Lopez AD. Burden of disease and injury in Aboriginal and Torres Strait Islander Peoples : the Indigenous health gap. Int J Epidemiol. 2009;38:470-7.

31. Hoy WE, Mott SA, Donald SPM. An expanded nationwide view of chronic kidney disease in Aboriginal Australians. Nephrology. 2016;21:916-22.

32. Cass A, Cunningham J, Snelling P, et al. Renal Transplantation for Indigenous Australians : Identifying the Barriers to Equitable Access. Ethn Heal. 2003;8:111-99.

This article is protected by copyright. All rights reserved. 
33. Barraclough KA, Hons M, Grace BS, et al. Residential Location and Kidney Transplant Outcomes in Indigenous Compared With Nonindigenous Australians. Transplantation. 2016;100:2168-76.

34. Devitt J, Anderson K, Cunningham J, Preece C, Snelling P, Cass A. Difficult conversations : Australian Indigenous patients ' views on kidney transplantation. BMC Neprhology. BMC Nephrology; 2017;18:310:1-14.

35. Australian Bureau of Statistics. 2016 Aboriginal and Torres Strait Islander Population Data Summary [Internet]. 2017 [Cited 2018 Jan 14]. Available from: http://www.abs.gov.au/ausstats/abs@.nsf/Lookup/by\%20Subject/2071.0 2016 Main\%20Fe atures $\sim$ Aboriginal\%20and\%20Torres\%20Strait\%20Islander\%20Population\%20Data\%20Summ ary 10

36. Garg PP, Furth SL, Fivush BA, Powe NR. Impact of Gender on Access to the Renal Transplant Waiting List for Pediatric and Adult Patients. J Am Med Assoc. 2000;11:958-64.

37. Segev DL, Kucirka LM, Oberai PC, et al. Age and Comorbidities Are Effect Modifiers of Gender Disparities in Renal Transplantation. J Am Soc Nephrol. 2009;20:621-8.

38. Kayler LK, Rasmussen CS, Dykstra M, et al. Gender Imbalance and Outcomes in Living Donor Renal Transplantation in The United States. Am J Transplant. 2003;3:452-8.

39. Puoti F, Ricci A, Nanni-costa A, Ricciardi W, Malorni W, Ortona E. Organ transplantation and gender differences : a paradigmatic example of intertwining between biological and sociocultural determinants. Biol Sex Differ. Biology of Sex Differences; 2016;7:35:1-5.

40. Norris K, Nissenson AR. Race, Gender, and Socioeconomic Disparities in CKD in the United 
States. J Am Med Assoc. 2008;19:1261-70.

41. Cobo G, Hecking M, Port FK, et al. Sex and gender differences in chronic kidney disease : progression to end-stage renal disease and haemodialysis. Clin Sci. 2016;130:1147-63.

42. Grace BS, Clayton PA, Cass A, McDonald SP. Transplantation rates for living- but not deceased-donor kidneys vary with socioeconomic status in Australia. Kidney Int. 2013;83:138-45.

43. Waterman AD, Peipert JD, Hyland SS, Mccabe MS, Schenk EA, Liu J. Modifiable Patient Characteristics and Racial Disparities in Evaluation Completion and Living Donor Transplant. Clin J Am Soc Nephrol. 2013;8:995-1002.

Table Legends:

Table 1: Demographics and clinical characteristics of Australian adult incident renal replacement therapy patients (2005-2015). RRT renal replacement therapy; GN glomerulonephritis; PKD polycystic kidney disease; VUR vesicoureteric reflux; SEIFA socioeconomic indexes for area (lower indices indicate greater disadvantage)

Table 2: First observed outcome and median time to event for adult incident renal replacement therapy patients (2005-2015). Censored patients are those who were lost to follow up prior to experiencing an event or who remained on dialysis at the conclusion of the follow up period. Note that 54\% of living donor transplants performed without patients being waitlisted were pre-emptive, hence median time to event is 0 days. IQR interquartile range.

This article is protected by copyright. All rights reserved. 
Table 3: Results of competing risk regression univariate and multivariate models. Note that subhazard ratios for States are referenced to the balanced grand mean for all states. LDTx living donor transplantation; SHR sub hazard ratio; PKD polycystic kidney disease; VUR vesicoureteric reflux; SEIFA socioeconomic indexes for area; RRT renal replacement therapy. ${ }^{*} p$ value $<0.05{ }^{* *} p$ value $<0.01$

Figure Legends:

Figure 1: First observed outcome at selected time points following commencement of renal replacement therapy by age group. Not that only patients with sufficient duration of follow up to capture all events are included. RRT renal replacement therapy

Figure 2: Cumulative incidence of each competing outcome for all adult patients commencing renal replacement therapy in Australia July 2006-July 2015 by age group. Note differences in Y axes. RRT, renal replacement therapy.

This article is protected by copyright. All rights reserved. 


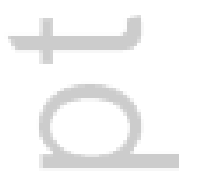

4 
$\underline{\text { Table } 1}$

\begin{tabular}{|c|c|}
\hline $\begin{array}{l}\text { Total Number of Incident } \\
\text { Patients }\end{array}$ & 21,213 \\
\hline \multicolumn{2}{|l|}{ Age at RRT, median (IQR) } \\
\hline & $63(51,73)$ \\
\hline \multicolumn{2}{|l|}{ Age categories } \\
\hline $18-24$ & $385(1.8 \%)$ \\
\hline $25-39$ & $1694(8.0 \%)$ \\
\hline $40-54$ & $4501(21.2 \%)$ \\
\hline $55-64$ & $4812(22.7 \%)$ \\
\hline $65-74$ & $5263(24.8 \%)$ \\
\hline$>=75$ & $4558(21.5 \%)$ \\
\hline \multicolumn{2}{|l|}{ Gender } \\
\hline Female & $8102(38.2 \%)$ \\
\hline \multicolumn{2}{|l|}{ Primary renal disease } \\
\hline GN & $4690(22.2 \%)$ \\
\hline PKD/VUR & $1945(9.2 \%)$ \\
\hline Diabetes & $7422(35.1 \%)$ \\
\hline Other & $7075(33.5 \%)$ \\
\hline \multicolumn{2}{|l|}{ Ethnicity } \\
\hline Non-Indigenous & 18895 (89.8\%) \\
\hline Indigenous & $2153(10.2 \%)$ \\
\hline \multicolumn{2}{|l|}{ BMI categories } \\
\hline Underweight & $602(2.9 \%)$ \\
\hline Normal & $6537(31.3 \%)$ \\
\hline Overweight & $6802(32.6 \%)$ \\
\hline Obese & $6913(33.1 \%)$ \\
\hline \multicolumn{2}{|c|}{ Comorbidities at Commencing RRT } \\
\hline Vascular Comorbidity & 10673 (50.5\%) \\
\hline Comorbid diabetes & $2444(11.6 \%)$ \\
\hline Chronic Lung Disease & $3503(16.6 \%)$ \\
\hline History of non-skin Cancer & $3503(16.6 \%)$ \\
\hline \multicolumn{2}{|l|}{ Smoking History } \\
\hline Never Smoked & $9660(46.1 \%)$ \\
\hline Current Smoker & $2547(12.1 \%)$ \\
\hline Former Smoker & $8761(41.8 \%)$ \\
\hline \multicolumn{2}{|l|}{ Referral Timing } \\
\hline Late Referral & $4304(20.5 \%)$ \\
\hline
\end{tabular}

This article is protected by copyright. All rights reserved. 
State

$\begin{array}{rc}\text { NT } & 758(3.6 \%) \\ \text { NSW } & 6652(31.4 \%) \\ \text { VIC } & 5018(23.7 \%) \\ \text { QLD } & 4061(19.1 \%) \\ \text { SA } & 1568(7.4 \%) \\ \text { WA } & 2273(10.7 \%) \\ \text { TAS } & 420(2.0 \%) \\ \text { ACT } & 463(2.2 \%)\end{array}$

SEIFA based on post code of residence

$\begin{array}{rrr}\text { 1st Quintile } & 5042(23.9 \%) \\ \text { 2nd Qunitile } & 4173(19.8 \%) \\ \text { 3rd Quintile } & 4195(19.9 \%) \\ \text { 4th Quintile } & 3912(18.6 \%) \\ \text { Remoteness } & \text { 5th Quintile } & 3739(17.8 \%) \\ & \text { Major city } & 14025(66.5 \%) \\ \text { Regional } & 5805(27.5 \%) \\ \text { Remote } & 1255(6.0 \%)\end{array}$

This article is protected by copyright. All rights reserved. 
Table 2

First Observed Outcome

Waitlisted

Living donor transplant without being waitlisted

Death without being waitlisted

Censored

Total
Number Percentage

4361

1239

7800

7813

21213

20.6

5.8 100
Median time to event, Days (IQR) $296(139,572)$

$0(0,205)$

$774(318,1364)$

$1074(554,1839)$ 
Table 3

\begin{tabular}{|c|c|c|c|c|c|c|c|c|}
\hline & \multicolumn{2}{|c|}{ Univariate } & \multicolumn{2}{|c|}{ Model 1} & \multicolumn{2}{|c|}{ Model 2} & \multicolumn{2}{|c|}{ Model 3} \\
\hline & \multicolumn{2}{|c|}{ Outcome: Waitlisting } & \multicolumn{2}{|c|}{ Outcome: Waitlisting } & \multicolumn{2}{|c|}{ Outcome: LDTX } & \multicolumn{2}{|c|}{$\begin{array}{c}\text { Outcome: Waitlisting or } \\
\text { LDTx }\end{array}$} \\
\hline & \multicolumn{2}{|c|}{$\begin{array}{c}\text { Competing Risk: LDTx, } \\
\text { Death }\end{array}$} & \multicolumn{2}{|c|}{$\begin{array}{c}\text { Competing Risk: LDTx, } \\
\text { Death }\end{array}$} & \multicolumn{2}{|c|}{$\begin{array}{l}\text { Competing Risk: } \\
\text { Waitlisting, Death }\end{array}$} & \multicolumn{2}{|c|}{ Competing Risk: Death } \\
\hline & SHR & $95 \% \mathrm{Cl}$ & SHR & $95 \% \mathrm{Cl}$ & SHR & $95 \% \mathrm{Cl}$ & SHR & $95 \% \mathrm{Cl}$ \\
\hline \multicolumn{9}{|l|}{ Age Category } \\
\hline $18-24$ & $1.98 * *$ & $1.71,2.30$ & 0.91 & $0.77,1.08$ & $2.17 * *$ & $1.75,2.68$ & $1.36 * *$ & $1.18,1.58$ \\
\hline $25-39$ & $1.41^{* *}$ & $1.30,1.54$ & 0.93 & $0.85,1.02$ & $1.57^{* *}$ & $1.36,1.83$ & $1.18^{* *}$ & $1.09,1.28$ \\
\hline $40-54$ & \multicolumn{8}{|c|}{ Reference } \\
\hline $55-64$ & $0.69 * *$ & $0.65,0.74$ & $0.83 * *$ & $0.77,0.90$ & $0.74^{* *}$ & $0.64,0.87$ & $0.76 * *$ & $0.71,0.81$ \\
\hline $65-74$ & $0.16 * *$ & $0.14,0.18$ & $0.2^{* *}$ & $0.18,0.22$ & $0.24^{* *}$ & $0.19,0.30$ & $0.16 * *$ & $0.15,0.18$ \\
\hline$>=75$ & $<0.01^{* *}$ & $0.00,0.01$ & $<0.01 * *$ & $0.00,0.01$ & $<0.01^{* *}$ & $0.00,0.02$ & $<0.01^{* *}$ & $0.00,0.01$ \\
\hline \multicolumn{9}{|l|}{ Gender } \\
\hline Female & $0.91^{* *}$ & $0.85,0.96$ & $0.85 * *$ & $0.80,0.91$ & $0.84^{* *}$ & $0.75,0.95$ & $0.81 * *$ & $0.77,0.86$ \\
\hline \multicolumn{9}{|l|}{ Ethnicity } \\
\hline Non- Indigenous & \multicolumn{8}{|c|}{ Reference } \\
\hline Indigenous & $0.36 * *$ & $0.31,0.41$ & $0.46 * *$ & $0.38,0.55$ & $0.11 * *$ & $0.05,0.24$ & $0.36^{* *}$ & $0.31,0.43$ \\
\hline \multicolumn{9}{|l|}{ Body Mass Index } \\
\hline Underweight & 0.88 & $0.74,1.06$ & $0.81^{*}$ & $0.67,0.97$ & 0.81 & $0.58,1.13$ & $0.75^{* *}$ & $0.64,0.88$ \\
\hline Normal & \multicolumn{8}{|c|}{ Reference } \\
\hline
\end{tabular}

This article is protected by copyright. All rights reserved. 
Overweight

Obese

Primary Renal Disease

Glomerulonephritis

PKD/VUR

Diabetes

Other

Comorbidities

Vascular Comorbidity

Comorbid Diabetes

Chronic Lung Disease

History of Cancer (1st Year)

History of Cancer (After 1st Year)

Smoking Status

Current Smoker (1st Year)

Current Smoker (After 1st Year)

Former Smoker (1st Year)

Former Smoker (After 1st Year)

Late Referral

Late Referral (1st 6 months)

Late Referral (6-12 months)

Late Referral (After 12 months)

Socioeconomic Disadvantage

SEIFA 1st Quintile

\begin{tabular}{|c|c|c|c|c|c|c|c|}
\hline 0.96 & $0.89,1.03$ & 1.06 & $0.98,1.14$ & 1.07 & $0.94,1.22$ & 1.07 & $1.00,1.14$ \\
\hline $0.76 * *$ & $0.70,0.81$ & $0.83 * *$ & $0.76,0.89$ & $0.61 * *$ & $0.52,0.71$ & $0.69 * *$ & $0.64,0.74$ \\
\hline \multicolumn{8}{|c|}{ Reference } \\
\hline $1.66 * *$ & $1.53,1.80$ & $1.12 *$ & $1.03,1.22$ & $1.32 * *$ & $1.15,1.51$ & $1.28 * *$ & $1.19,1.38$ \\
\hline $0.22 * *$ & $0.20,0.23$ & $0.38 * *$ & $0.34,0.41$ & $0.32 * *$ & $0.26,0.41$ & $0.33^{* *}$ & $0.30,0.36$ \\
\hline $0.3^{* *}$ & $0.28,0.33$ & $0.68 * *$ & $0.62,0.74$ & $0.69 * *$ & $0.59,0.81$ & $0.64 * *$ & $0.59,0.69$ \\
\hline $0.22 * *$ & $0.20,0.23$ & $0.54 * *$ & $0.50,0.58$ & $0.54 * *$ & $0.45,0.64$ & $0.48 * *$ & $0.45,0.52$ \\
\hline $0.43 * *$ & $0.38,0.49$ & $0.56 * *$ & $0.49,0.64$ & 0.77 & $0.60,1.00$ & $0.56 * *$ & $0.49,0.63$ \\
\hline $0.32 * *$ & $0.29,0.36$ & $0.62 * *$ & $0.55,0.69$ & $0.49 * *$ & $0.37,0.65$ & $0.57 * *$ & $0.51,0.64$ \\
\hline $0.17 * *$ & $0.13,0.22$ & $0.28 * *$ & $0.22,0.36$ & $0.51 * *$ & $0.36,0.73$ & $0.3^{* *}$ & $0.25,0.38$ \\
\hline $0.59 * *$ & $0.49,0.71$ & $0.76 *$ & $0.63,0.93$ & 1.1 & $0.63,1.94$ & $0.62 * *$ & $0.52,0.74$ \\
\hline $0.6 * *$ & $0.52,0.69$ & $0.47 * *$ & $0.41,0.55$ & $0.19 * *$ & $0.14,0.27$ & $0.35^{* *}$ & $0.30,0.40$ \\
\hline $1.15^{*}$ & $1.00,1.31$ & 1 & $0.86,1.15$ & 0.96 & $0.57,1.62$ & $0.57^{* *}$ & $0.50,0.65$ \\
\hline $0.68 * *$ & $0.63,0.73$ & $0.81 * *$ & $0.75,0.88$ & $0.7^{* *}$ & $0.62,0.81$ & $0.83 * *$ & $0.77,0.89$ \\
\hline 1.03 & $0.94,1.14$ & $1.67 * *$ & $1.50,1.86$ & $2.29 * *$ & $1.63,3.23$ & 1.1 & $1.00,1.22$ \\
\hline $0.38 * *$ & $0.33,0.45$ & $0.45^{* *}$ & $0.39,0.53$ & $0.17^{* *}$ & $0.13,0.24$ & $0.32 * *$ & $0.28,0.37$ \\
\hline $0.8^{* *}$ & $0.69,0.92$ & 0.86 & $0.74,1.00$ & 0.77 & $0.51,1.17$ & $0.63 * *$ & $0.55,0.73$ \\
\hline $1.31 * *$ & $1.17,1.46$ & $1.22 * *$ & $1.09,1.37$ & $1.74 * *$ & $1.23,2.47$ & 0.94 & $0.85,1.05$ \\
\hline $0.85^{* *}$ & $0.78,0.94$ & 0.98 & $0.88,1.08$ & $0.66 * *$ & $0.53,0.80$ & $0.85^{* *}$ & $0.78,0.93$ \\
\hline
\end{tabular}

This article is protected by copyright. All rights reserved. 


\begin{tabular}{|c|c|c|c|c|c|c|c|c|}
\hline \multirow[t]{2}{*}{ SEIFA 2nd Quintile } & 1.08 & $0.98,1.18$ & $1.15^{*}$ & $1.04,1.27$ & 0.91 & $0.75,1.10$ & 1.08 & $0.99,1.18$ \\
\hline & \multicolumn{8}{|c|}{ Reference } \\
\hline SEIFA 4th Quintile & $1.15^{* *}$ & $1.04,1.26$ & 1.02 & $0.92,1.13$ & $1.33^{* *}$ & $1.11,1.58$ & $1.16 * *$ & $1.06,1.26$ \\
\hline SEIFA 5th Quintile & $1.22 * *$ & $1.11,1.34$ & 1.01 & $0.91,1.12$ & $1.52^{* *}$ & $1.28,1.81$ & $1.24 * *$ & $1.13,1.35$ \\
\hline \multicolumn{9}{|l|}{ Remoteness } \\
\hline Urban & \multicolumn{8}{|c|}{ Reference } \\
\hline Regional & $0.83^{* *}$ & $0.78,0.89$ & $0.88^{* *}$ & $0.81,0.95$ & $1.33 * *$ & $1.15,1.53$ & 1.01 & $0.94,1.08$ \\
\hline Remote & $0.41 * *$ & $0.35,0.49$ & 0.81 & $0.63,1.04$ & 0.86 & $0.47,1.59$ & 0.89 & $0.71,1.12$ \\
\hline \multicolumn{9}{|l|}{ State } \\
\hline Northern Territory & $0.5^{* *}$ & $0.41,0.61$ & 0.83 & $0.65,1.07$ & 0.64 & $0.35,1.16$ & $0.72^{* *}$ & $0.57,0.90$ \\
\hline New South Wales & $1.14^{* *}$ & $1.07,1.23$ & $1.13 * *$ & $1.04,1.22$ & $0.79 * *$ & $0.68,0.91$ & 1.01 & $0.95,1.09$ \\
\hline Victoria & $1.43 * *$ & $1.33,1.53$ & $1.22 * *$ & $1.12,1.32$ & 1.07 & $0.93,1.23$ & $1.22 * *$ & $1.14,1.30$ \\
\hline Queensland & 1.01 & $0.93,1.09$ & 1 & $0.92,1.09$ & $0.6^{* *}$ & $0.51,0.72$ & $0.82 * *$ & $0.76,0.89$ \\
\hline South Australia & $1.45 * *$ & $1.31,1.61$ & $1.37 * *$ & $1.22,1.53$ & 1.2 & $0.99,1.46$ & $1.42 * *$ & $1.28,1.56$ \\
\hline Western Australia & $0.82 * *$ & $0.74,0.91$ & $0.76^{* *}$ & $0.68,0.85$ & 1.16 & $0.98,1.38$ & $0.82 * *$ & $0.75,0.90$ \\
\hline Tasmania & 0.91 & $0.74,1.12$ & $0.77^{*}$ & $0.62,0.97$ & $2.24^{* *}$ & $1.74,2.87$ & $1.21 *$ & $1.03,1.42$ \\
\hline Australian Capital Territory & 1.13 & $0.95,1.35$ & 1.08 & $0.89,1.31$ & 0.99 & $0.71,1.38$ & 0.97 & $0.81,1.16$ \\
\hline \multicolumn{9}{|l|}{ Year of Commencing RRT } \\
\hline Per Year & 1 & $0.99,1.02$ & & & & & & \\
\hline
\end{tabular}




\section{University Library}

\section{- M M N E R VA A gateway to Melbourne's research publications}

Minerva Access is the Institutional Repository of The University of Melbourne

Author/s:

Sypek, MP;Clayton, PA;Lim, W;Hughes, P;Kanellis, J;Wright, J;Chapman, J;McDonald, SP

Title:

Access to waitlisting for deceased donor kidney transplantation in Australia

Date:

2019-07-01

Citation:

Sypek, M. P., Clayton, P. A., Lim, W., Hughes, P., Kanellis, J., Wright, J., Chapman, J. \& McDonald, S. P. (2019). Access to waitlisting for deceased donor kidney transplantation in Australia. NEPHROLOGY, 24 (7), pp.758-766. https://doi.org/10.1111/nep.13484.

Persistent Link:

http://hdl.handle.net/11343/285778 